\title{
A biopolítica da população e a experimentação com seres humanos
}

\author{
The bio-power of population \\ and experiments with human beings
}

\begin{abstract}
Taking as starting points the Foucault's concept of bio-power of population, the Giorgio Agamben's considerations about nude life and the Hannah Arendt's comprehension of human condition, we analyze experiments with human beings that were made in the beginning and in the end of twenty century. Initially, we discuss the experiments that were made in India, between 1894 and 1899, for determinate the Anopheles role in the transmission of malaria. Finally, we analyze the way by which recently, in Africa, were conducted researches over pregnant women infected by the HIV.

Key words Bio-power, Nude life, History of medicine, Experimentation with human beings
\end{abstract}

Resumo A partir do conceito foucaultiano de biopolítica da população, das considerações de Giorgio Agamben (2002) sobre a vida nua e estado de exceção, assim como das teses de Hannah Arendt relativas à condição humana, analisamos dois estudos experimentais com seres humanos realizados em inícios e fins do século 20. Inicialmente nos referimos às experimentações realizadas na Índia entre 1894 e 1899 para determinar o papel do Anopheles na transmissão da malária. Por fim, analisamos um estudo de transmissão vertical de HIV recentemente realizado na África com mulheres grávidas portadoras do vírus. Palavras-chave Biopolítica, Vida nua, História da medicina, Experimentação com seres humanos

\footnotetext{
1 Departamento de Saúde Pública da Universidade Federal de Santa Catarina. Campus Universitario

Trindade. Caixa Postal 476. 88040-900

Florianópolis SC.

sandracaponi@newsite. com.br
} 


\section{Introdução}

Sem dúvida a problemática da experimentação com seres humanos é uma das questões de maior peso nas discussões atuais da bioética. De fato, podemos dizer que a bioética se estrutura como um espaço de saber autônomo e independente a partir do momento em que a sociedade se defronta com a existência de experimentações abusivas com seres humanos e com a necessidade de estabelecer limites claros entre o que pode e o que não pode ser admitido. Dentre essas experimentações que foram divulgadas e conhecidas fundamentalmente a partir dos anos 70, quiçá a mais discutida foi o estudo de história natural da sífilis realizado numa comunidade negra do Estado de Alabama entre 1932 e 1972, conhecido como Caso Tuskegee (Goldim, 1999). Muito antes, as Declarações de Nuremberg e de Helsinque já tinham estabelecido os fundamentos legais e éticos das pesquisas com seres humanos como resposta aos horrores cometidos nos campos de extermínio durante a Segunda Guerra Mundial. Já no inicio dos anos 70 surgem diversas reflexões sobre experimentação com seres humanos entre as quais podemos destacar as Reflexões filosóficas sobre a experimentação com seres humanos de Hans Jonas (1970).

A problemática da experimentação com seres humanos é um dos temas recorrentes nas discussões da bioética. Do momento que surge esta disciplina até hoje, diversos estudos foram dedicados à problemática abordando as declarações e as legislações, estudando os limites aos quais devem se submeter as pesquisas e os pesquisadores, explicitando questões relativas à metodologia das pesquisas ou às exigências especificas para cada tipo particular de experimentação (Vieira \& Hossne, 1987; Berlinguer, 1996; Freitas \& Hossne, 1998; Lecourt, 2000; Nouvel, 2000; Benoit-Browaeys, 2001; Goldim \& Rossi 1999; Amann, 2001; Rothman, 2001; Garrafa, 2001; Salomon-Bayet, 2003). Neste trabalho não pretendemos analisar essa extensa literatura proveniente da bioética da qual mencionamos só alguns nomes, tentaremos refletir sobre nosso presente, a partir da análise de certas experimentações realizadas no passado tomando como eixo de análise o conceito de biopolítica das populações.

Tentaremos analisar as condições históricas que permitiram legitimar a existência de práticas de submissão dos indivíduos em nome do bem comum, da saúde e do vigor das popula- ções. Particularmente, centraremos nosso estudo na questão do uso experimental de seres humanos como cobaias para a realização de pesquisas médicas. Assim, tomando como ponto de partida o conceito foucaultiano de biopoder pretendemos analisar as experimentações realizadas na Índia no fim do século 19 (1894-1899) para determinar o papel que o Anopheles ocupava na transmissão da malária. Analisaremos também de que modo, cem anos mais tarde, no fim do século 20 (1998-2000) foram conduzidas as pesquisas sobre HIV na África a partir de um estudo com mulheres grávidas portadoras do vírus. Esses estudos suscitaram críticas da comunidade científica às quais os pesquisadores responderam defendendo a necessidade de aceitar a existência do chamado "relativismo ético" ou "duplo standard" (Amann, 2001; Rothman, 2001; Garrafa, 2001). Argumenta-se que é possível não aceitar as normas que constam na Declaração de Helsinque (1996) por tratar-se de pesquisas realizadas em sociedades pobres, sem condições de ministrar assistência à população, cujos governos se manifestam favoráveis à realização das mesmas (Amann, 2001).

Esta situação nos coloca diante do dilema de legitimar a existência de dois mundos: um regido por leis e normas éticas e outro ao qual essas normas, nesse caso específico da Declaração de Helsinque (1996), não se aplicam.

Tomamos como ponto de partida certa proximidade que parece evidenciar-se entre as pesquisas que aceitam e defendem a existência do "duplo standard" e aquelas realizadas no fim do século 19 e início do século 20 com as populações nativas das colônias. Como tentaremos analisar aqui, hoje resulta necessário criar artifícios teóricos para legitimar aquilo que no século 19 não precisava ser justificado, pois era aceito por todos. A existência de uma população cuja saúde exige cuidados, corpos que devem ser maximizados e melhorados, e a existência de populações e indivíduos considerados postos "fora da jurisdição humana" (Agamben, 2002).

Acreditamos que o conceito foucaultiano de biopolítica da população, as reflexões de Giorgio Agamben (2002) sobre o que denomina vida nua e estado de exceção, assim como os estudos que Hannah Arendt dedica à compreensão da condição humana, podem nos auxiliar na tarefa de tentar entender as condições históricas que legitimaram práticas de submissão dos sujeitos em nome do bem comum, da 
saúde das populações, do futuro da espécie ou da vitalidade do corpo social (Foucault, 1978).

\section{A biopolítica da população}

O conceito de biopolítica foi enunciado pela primeira vez numa conferência que Foucault ministrou em 1974 na Universidade Estadual de Rio de Janeiro. A palestra foi publicada em 1977 com o nome de $O$ nascimento da medicina social (Foucault, 1989). Nesse texto Foucault aponta um deslocamento significativo nas estratégias de poder, o controle da sociedade sobre os indivíduos não se opera simplesmente pela consciência ou pela ideologia, mas começa no corpo, com o corpo. Foi no biológico, no somático, no corporal que, antes de tudo, investiu a sociedade capitalista. O corpo é uma realidade biopolítica (Foucault, 1989). Porem, será no quinto capitulo da Vontade de saber que Foucault esclarece e aborda detidamente o conceito de biopoder por oposição ao direito de morte que caracterizaria o poder do soberano (Michaud, 2000). Por fim, essa temática será retomada no curso do College de France dos anos 75 e 76, dedicado à problemática da guerra de raças e das suas relações com o biopoder (Foucault, 1992); no curso dos anos 77-78 "Segurança, território e população", e no curso dos anos 7879 dedicado ao nascimento da biopolítica (Foucault, 1997).

Como afirma Didier Fassin (2003), as leituras contemporâneas do conceito de biopoder se limitaram a utilizar essa referência em diferentes contextos sem ter feito uma abordagem teórica ou conceitual do mesmo, com exceção de dois autores provenientes da tradição filosófica - Agnes Heller (1994) e Giorgio Agamben (2002). Não deixa de ser significativo que as duas obras que mais contribuiram para repensar esse conceito se inspiram no trabalho de Hannah Arendt que fundou paralelamente a Foucault uma teoria do governo referido á vida (Fassin, 2003). Será na articulação entre o conceito foucaultiano de biopoder, a releitura de Agamben do mesmo e as preocupações de Arendt sobre a política e a vida que tentaremos nos situar para analisarmos dois estudos experimentais com seres humanos realizados no início e fins do século 20.

Para compreender a existência de certa proximidade entre as pesquisas realizadas no fim do século 19 e inícios do século 20 nas colônias de ultramar e aquelas realizadas recentemente na África resulta indispensável falar de um poder sobre a vida preocupado com os mecanismos que podem contribuir para melhor modelar os corpos e melhor controlar e conhecer os fenômenos populacionais. A partir do fim do século 18 , inicia-se uma nova administração dos corpos e uma nova "gestão calculada da vida" (Foucault, 1978), essa nova administração permite a emergência de uma rede de saber sobre as populações que inclui os estudos estatísticos sobre demografia; as taxas diferenciais de mortalidade; os registros de nascimento e doenças; o conhecimento da distribuição, concentração e controle das epidemias.

Então, e pela primeira vez na história, o biológico ingressa no registro da política: a vida passa a entrar no espaço do controle de saber e da intervenção do poder. O sujeito, na qualidade de sujeito de direitos, passa a ocupar um segundo plano em relação à preocupação política por maximizar o vigor e a saúde das populações. Deveríamos falar de biopolítica para designar o que faz com que a vida e seus mecanismos possam entrar no domínio de cálculos explícitos, e o que transforma o saber-poder num agente de transformação da vida humana (Foucault, 1978). Os estudos e as estratégias eugênicas são as que melhor definem as características dessa biopolítica da população que, ao mesmo tempo em que se propõe o melhoramento da raça e da espécie, parece precisar do controle e da submissão de corpos sem direito que se configuram como simples vida nua, vida que se mantém nas margens, vida que pode ser submetida e aniquilada.

Uma característica do biopoder é a importância crescente da norma sobre a lei. A idéia de que é preciso definir e redefinir o normal em contraposição àquilo que se lhe opõe, a figura dos anormais, incorporada logo à categoria de degeneração que se inscreve nas margens do jurídico. Esses sujeitos se definem, como afirma Agamben, por seu caráter de "exceção". Lembremos que: a exceção se situa em posição simétrica em relação ao exemplo, com o qual forma um sistema. Esta constitui um dos modos pelos quais um conjunto procura fundamentar e manter a própria coerência (Agamben, 2002). Mas, ela tem uma função estratégica, ela auxilia na conformação da identidade de um grupo, pois a relação de exceção é uma relação de bando. Aquele que foi banido não é, na verdade, simplesmente posto fora da lei e indiferente a esta, mas é abandonado por ela, ou seja, exposto e colocado em risco no limiar em que vida e direito, interno e externo se confundem (Agamben, 2002). 


\section{Os biopoderes e a doença tropical}

A percepção do corpo na perspectiva populacional sofrerá, na última década do século $19 \mathrm{e}$ nas primeiras décadas do século 20, uma alteração diretamente vinculada à criação de centros de pesquisa europeus nas colônias de ultramar, que pouco a pouco começavam a ser ocupadas por europeus brancos. A colonização deixou, nos corpos desses primeiros colonos, marcas de doenças exóticas e desconhecidas que se transformaram em objeto de estudo privilegiado dos principais institutos metropolitanos e dos médicos militares enviados aos trópicos.

Os estudos estatísticos evidenciavam que a suscetibilidade às doenças dos europeus brancos, que pretendiam habitar os trópicos, duplicava as mortes dos habitantes originários dos territórios conquistados, impulsionando a criação, a partir do estabelecimento do primeiro Instituto Pasteur da Argélia, no ano de 1894, de uma série de institutos de pesquisa europeus nas colônias de ultramar. A Inglaterra, por sua vez, enviou seus médicos militares às colônias da Índia para estudar fundamentalmente a malária.

Com a Fundação da The London School of Tropical Medicine em 1898, Patrick Manson inaugura formalmente os estudos de medicina tropical. Anos antes, Manson tinha impulsionado outro médico militar, Ronald Ross, a iniciar uma série de pesquisas na Índia para determinar o rol do mosquito na transmissão da malária. Existe um interessante registro das dificuldades que Ross teve de enfrentar até chegar ao prêmio Nobel que, em 1902, lhe seria concedido pelo descobrimento do papel do Anopheles na propagação do paludismo aviário. Cada uma dessas dificuldades foram relatadas com paixão, temor e com as dúvidas que existiam na mente desses dois homens simples, ambiciosos e nacionalistas, nas correspondências que ambos mantiveram entre 1894 e 1899 (Bynum \& Overy, 1998).

Essas cartas, que foram cuidadosamente conservadas e arquivadas, e que foram recentemente publicadas (Bynum \& Overy, 1998), constituem hoje uma fonte valiosa para compreender algo a mais sobre a história das ciências e particularmente das doenças tropicais. Elas adquirem uma enorme relevância quando pensamos em realizar a história segundo os ensinamentos de Porter (2002), isto é, de baixo para cima. As cartas falam sobre a malária, o plasmodium, a hipótese do mosquito, sobre a ameaça representada pelos pesquisadores itali- anos e franceses; falam também das dificuldades de um pesquisador pouco preparado nos estudos da entomologia para reconhecer entre a multiplicidade de insetos chupadores de sangue aquele que pudesse servir como agente intermediário vivo do paludismo.

Muitas dificuldades são relatadas, expectativas frustradas, medo do fracasso, necessidade de encontrar o inseto antes dos franceses e italianos, falta de clareza nos objetivos. Falam também da distância entre dois mundos, o mundo dos pesquisadores ingleses e a miséria dos povos colonizados, neste caso o povo indiano. Falam dos recursos disponíveis para os pesquisadores diante da extrema pobreza dos sujeitos que serão submetidos a tratamento e que serão, ao mesmo tempo, sujeitos de pesquisa. Essas cartas relatam a colaboração entre os dois pesquisadores, falam dos mosquitos que atravessavam o mar conservados em glicerina para serem observados por Manson (1898), narram as análises realizadas nos dois lados do mar e os estudos comparativos, falam do trabalho conjunto de dois intelectuais com um mesmo objetivo. Porém, revelam também as misérias da medicina imperial, as mentiras ditas aos supostos voluntários, as experiências com mosquitos infectados que levaram muitos à doença e à morte, falam da leviandade e da falta de cuidado com que eram tratados os povos colonizados. Elas revelam o lado oculto da pesquisa, o que não se fala publicamente, o que não faz parte da clássica e heróica história da medicina.

Então a tênue linha que separa a história interna das descobertas científicas realizadas na assepsia do laboratório, com protocolos bem delineados de pesquisa que se definem como imparciais e objetivos, se mistura com a história dos medos e das misérias humanas que estão por trás de certas descobertas científicas.

Poderíamos afirmar com Bruno Latour (1997) que essas cartas revelam a irracionalidade da pesquisa científica, que deixam transparecer a falta de objetividade do estudo e a precariedade do saber científico. Preferimos, pelo contrário, aceitar a tese de Pierre Bourdieu (2001) e observar esses documentos como elementos que podem contribuir para compreender melhor uma conquista científica.

Como afirma Bourdieu (2001) é necessário observar dois níveis no discurso científico. Inicialmente um discurso formal, que se vale da forma impessoal, reduzindo ao mínimo as intenções dos investigadores. Logo, aquele outro nível de discurso, que por muito tempo foi ex- 
cluído da história da ciência: o discurso privado, em que aparece o que não pode ser publicado. A historia da ciência centrou-se, classicamente, nos relatos formais, ocupando-se do discurso privado para exaltar o heroísmo e o valor dos grandes homens de ciência. Pelo contrário, os erros e fracassos foram sistematicamente esquecidos.

$\mathrm{Na}$ pesquisa sobre a malária, conjuga-se a relevância científica da descoberta, reconhecida anos mais tarde quando Ross conquista o prêmio Nobel (1902), com o discurso privado. As cartas revelam que para a conquista desse prêmio tudo era permitido, incluídos enganos e mentiras, como lemos na carta 203, quando Ross relata que havia afirmado para um doente que a picada de um mosquito infectado com malária o ajudaria em sua recuperação e o libertaria definitivamente dos parasitas da doença (Bynum \& Overy, 1998; Ross, carta 203).

Causa surpresa observar que, por exemplo, no caso das pesquisas realizadas no Brasil por Domingo Freire a partir de 1880, as experimentações realizadas com animais, particularmente a vivissecção, produziam mais rejeição e revolta do que aquelas realizadas com populações vulneráveis. Como afirma Benchimol (1999) em seu estudo sobre a febre amarela no Brasil: O uso de animais como fonte de conhecimento aplicável à biologia do homem provoca sarcasmos, ofende os pruridos morais dos padres, das beatas e dos provedores de muitos hospitais da cidade. O uso indiscriminado de pacientes internados nos hospitais como cobaias para as experiências dos clínicos (e bacteriólogos) não despertavam tanta indignação, uma vez que eram operários, imigrantes, marinheiros, escravos ou gente que trazia ainda a marca do cativeiro na cor e na aspereza da pele (Benchimol, 1999).

Não pretendemos realizar uma denúncia retrospectiva de faltas morais cometidas quando a problemática da ética na pesquisa ainda não era claramente tematizada, porém, é preciso afirmar com Benchimol que: mesmo assim, a compaixão ou o parti pris inspiravam constantes protestos contra a prática (uso de pacientes para pesquisa) que só fazia agravar o estigma dos hospitais: antecâmaras da morte, que a população encarava com compreensivel horror (Benchimol, 1999). De um modo mais ou menos sutil já se manifestava certa inquietação por essas estratégias de poder que legitimavam as intervenções sobre as populações pobres com o objetivo de produzir um conhecimento aplicável a todos. Como pode ser observado na breve car- ta de um cronista do Jornal do Commercio de 25 de março de 1880: irei em linha reta ao alvo que pretendo atingir, provar com fatos irrecusáveis que a pretendida invenção (...) é um martírio horrível (senão a morte!) imposto aos míseros enfermos (apud Benchimol, 1999).

Ainda existindo certa preocupação pela "legitimidade moral das experiências", elas eram realizadas sem dificuldade. No caso específico da correspondência entre Manson e Ross, não parece existir nenhum tipo de questionamento moral sobre a utilização da população pobre que habita nas colônias como objetos de pesquisa. Será preciso, então, tentar analisar e compreender as estratégias de poder que legitimaram a utilização de populações vulneráveis, pobres e imigrantes, para as pesquisas médicas. Tomando emprestadas as palavras de Giorgio Agamben em Homo Sacer, poderíamos afirmar que: a questão correta sobre os horrores cometidos não é, portanto, aquela que pergunta hipocritamente como foi possível cometer delitos tão atrozes para com os seres humanos; mais honesto e sobretudo mais útil seria indagar atentamente quais procedimentos jurídicos e quais dispositivos politicos permitiram que seres humanos fossem tão integramente privados de seus direitos e de suas prerrogativas, até o ponto em que cometer contra eles qualquer ato não mais se apresentava como delito (Agamben, 2002).

Os novos dispositivos políticos que aqui entram no jogo já não dizem respeito a sujeitos de direito, nem respeito de cidadãos que pertencem a uma determinada nação ou Estado. No registro da biopolítica da população, as leis são substituídas pelo império dos fatos, pela urgência e o imediatismo. O que entra em jogo aqui já não é o direito à vida ou à saúde dos pacientes, membros de uma comunidade política, o que se converte em objeto de pesquisa é, em palavras de Foucault, "o corpo espécie"; ou, em palavras de Agamben "vida nua"; o mesmo que para Hannah Arendt (1993) representa o espaço da necessidade vital muda e silenciosa. Isto é, o sujeito político foi identificado com o domínio das necessidades vitais, o corpo deixa de ser de alguém para ser transformado em um elemento na mecânica geral dos seres vivos que serve de suporte aos processos biológicos de nascimento, mortalidade, saúde, epidemias. O corpo individual importa só na medida em que ilustra os processos que podem acontecer em nível populacional; que podem indicar o modo de agir, de adoecer e de responder aos estímulos do conjunto da população. 
Os indivíduos deixaram de ser sujeitos de direito e passam a ser - no interior dessa biopolítica da população, analisada por Foucault como própria de fins do século 19 - corpo espécie, isto é, corpos transidos pela mecânica do vivente limitados a seu estatuto vital. A partir desse momento, os sujeitos submetidos a observação deixarão de ser sujeitos individuais para passar a ser corpos valiosos exclusivamente pela identidade vital que os unifica. Os corpos de Abdul Kadir ou do misterioso Lutchman, referenciados na correspondência entre Manson e Ross como sujeitos de pesquisa (Bynum \& Overy, 1998), têm um significado preciso, o que se revela neles, suas dores, seu sofrimento, o fato de tolerar ou não a exposição sistemática a mosquitos infestados, poderá ser de utilidade para os outros. Pode possibilitar a prosperidade e o desenvolvimento das colônias inglesas ou, pelo contrário, pode significar uma confirmação das teorias que falam da "periculosidade dos trópicos", de ameaças que não podem ser controladas e entre elas, a mais temida, a ameaça que a malária representa para o homem branco.

Se voltarmos, novamente, para a pergunta formulada por Agamben veremos que ela inclui duas questões. Primeiro, trata-se de analisar os dispositivos políticos que permitiram que essa ordem de coisas fosse aceita. Podemos responder essa questão por referência ao estreito vínculo que, a partir do século 19, se deu entre a vida, entendida como zoé, e a política. Em segundo lugar, deve ser questionado quem são esses sujeitos que foram privados de seus direitos. Veremos então que, ainda que o privilégio concedido ao elemento biológico possa apagar as diferenças, tornando o saber derivado desses corpos aplicável à humanidade como um todo, os sujeitos observados foram escolhidos entre a população pobre e necessitada de assistência no caso concreto das pesquisas de malária, a população indiana. Tanto os experimentos relatados por Manson e Ross em suas cartas, quanto outros estudos e observações realizados a propósito das doenças tropicais e de outras doenças contagiosas à semelhança do acontecido no nascimento da clínica conduzem à reiteração de uma mesma e velha pergunta:

Com que direito se pode transformar em objeto de observação clínica (ou em objeto de experimentação) um doente ao qual a pobreza obrigou a solicitar assistência hospitalar? Ele requer um auxílio do qual é o sujeito absoluto na medida em que este foi criado para ele; mas agora the é imposto um olhar do qual ele é objeto, e um objeto relativo, pois o que se decifra nele está destinado a um melhor conhecimento dos outros (Foucault,1978).

Do mesmo modo, para que pudessem existir os estudos relativos à distribuição das epidemias, ao reconhecimento de agentes causais específicos, à identificação de vetores, acreditava-se que seria indispensável poder contar com um grupo populacional que além de estar exposto a doenças, tivesse as mesmas características dos doentes que habitavam o Hospital Geral no momento da emergência da clínica. Era preciso contar com uma população pobre, necessitada de assistência e alheia ao espaço dos direitos.

A análise foucaultiana dos diferentes saberes e estratégias que compõem a chamada biopolítica da população pode ter um papel central para desnaturalizar as condições, não transcendentais nem necessárias, mas históricas e contingentes que possibilitaram a construção dos saberes relativos à saúde das populações.

Não existe um imperativo transcendental, nem uma exigência inevitável que seja uma precondição para a realização desses estudos. O que é poderia não ser. Para melhor compreender o caráter de "evento" desses modos de produzir um saber nada melhor do que analisar os mecanismos de poder que possibilitaram sua construção. Nem sempre os estudos relativos às epidemias utilizaram populações pobres ou necessitadas. Muitas vezes os próprios médicos dirigiram a si mesmos certos procedimentos de pesquisa mostrando o caráter contingente e evitável da utilização dessas populações.

Dizer que a assimetria social resultou na condição histórica de possibilidade do conhecimento médico referente às epidemias, e não sua condição necessária, significa afirmar a contingência e a "evitabilidade" desse modo de produzir o conhecimento científico. Não se trata de julgar o passado com as categorias morais atuais, trata-se de "eventualizar" nosso presente, de mostrar que aqueles procedimentos que aparecem, ao olhar de muitos pesquisadores, como naturais e evidentes, como a condição necessária de possibilidade para a construção do saber, têm uma historia recente que não precisa ser perpetuada nem naturalizada. 


\section{Atualidade da biopolítica}

Assim, quando analisamos o modo como recentemente foram construídas certas pesquisas de uma das epidemias emergentes que mais desafios apresentam para os pesquisadores, a AIDS, vemos reiterarem-se os mesmos procedimentos e argumentos que caracterizaram os estudos médicos e epidemiológicos do século 19 e inícios do século 20. Hoje as pesquisas com seres humanos relativas à AIDS concentram-se na África, onde a incidência da doença atinge, em algumas populações, até $50 \%$ dos habitantes.

Tudo parece ser permitido nessa lógica na qual os sujeitos necessitados podem ser utilizados em beneficio do melhoramento do vigor, da vida e da saúde das sociedades opulentas: um exercício de biopolítica da população, que reproduz as velhas estratégias de poder próprias do século 19, tão utilizadas e bem aceitas quando as pesquisas eram referidas aos sujeitos sem direito que habitavam as colônias pobres.

É o que parece estar ocorrendo na África. Tomemos como exemplo a pesquisa realizada nos anos 98-99, que envolveu 16 equipes de pesquisadores para a realização de um estudo sobre a efetividade de um tratamento reduzido de AZT no caso de mulheres aidéticas grávidas. A população estudada foi de 17.000 mulheres grávidas. Sabia-se, por estudos prévios, realizados em 1995, que o tratamento da mãe com AZT reduz em 66\% a transmissão de HIV para o filho. O custo desse tratamento era de oitocentos dólares. E o objetivo da nova pesquisa era determinar se um tratamento curto com AZT (por um valor de cinqüenta dólares) poderia garantir uma redução da transmissão. Partiu-se da hipótese de que por ocorrer a transmissão no fim da gravidez e no momento do parto, um tratamento curto seria tão eficaz quanto um tratamento longo (Rothman, 2001).

A população foi dividida em dois grupos, $\mathrm{o}$ grupo de observação no qual se aplicaria o tratamento curto, e o grupo controle. Para este último, existiam duas alternativas, ou um tratamento completo (longo), ou o uso de placebo. Por avaliação de custos escolheu-se a segunda alternativa. Isso significa que os sujeitos que participavam do grupo controle não sabiam se estavam ou não sendo tratados. Foi constatado que o tratamento curto reduz em 50\% a transmissão, isto é, ele é menos eficaz que o tratamento longo, porém 50\% mais eficaz que o não tratamento. Desta forma, as crianças que nasceram do grupo controle foram, em sua maioria, HIV-positivas. Segundo Márcia Angell: os pesquisadores violaram os princípios de Helsinque e demonstraram possuir um desprezo desumano pelo bem dos pacientes (apud Rothman, 2001). Como afirmam Garrafa e Machado (2001): A perplexidade manifestada no referido editorial aconteceu porque um estudo de tal natureza não poderia ter sido realizado nos Estados Unidos, ou em qualquer outro país desenvolvido, onde seria esperado que esses pacientes com HIV fossem alertados e tratados.

De fato, a resposta dada à demanda internacional sobre um posicionamento ético dos pesquisadores quando se questionou os limites os quais toda pesquisa deve respeitar foi a seguinte: Nossas pesquisas não são realizadas conforme as regras da ética? Pois bem, mudemos as regras da ética (apud Rothman, 2001).

A dificuldade está na nova posição geográfica dos pesquisadores americanos e europeus que até os anos 90 conduziam suas pesquisas com sujeitos de seus próprios países. O peso econômico e as restrições éticas e legais que são exigidas no Primeiro Mundo não são idênticas às exigidas nos países pobres. Aquilo que antes da Declaração de Helsinque (e ainda depois desta declaração como o evidencia o Caso Tuskegee) podia acontecer no interior de cada país com as populações consideradas marginais e que décadas de discussão impediram de continuar a acontecer, hoje foi deslocado dos indivíduos que estão nas margens da sociedade (loucos, delinqüentes, crianças) para as populações carentes dos países localizados nas margens do mundo: os países mais pobres do Terceiro Mundo.

Lembremos que a Declaração de Helsinque, de 1964, afirma que o bem-estar de cada sujeito (pertença ou não a um grupo vulnerável) deve prevalecer sobre as necessidades da ciência ou da sociedade. No entanto, parece que quando passamos essa afirmação para escala planetária, ela tende a perder sua força.

$\mathrm{Na}$ medida em que se pretenda restringir a validade dessa declaração para determinadas regiões do mundo e considerar que outras regiões podem ter menores exigências éticas na realização de suas pesquisas, essas populações situadas nas margens deixam de ser pensadas como sujeitos de direito para passarem a ser consideradas exclusivamente em termos de corpos vivos que para poder contar com algum tipo de assistência devem contribuir para a construção de um conhecimento aplicável a to- 
dos. O poder de morte aparece como complemento de um poder que se exerce positivamente sobre a vida, que procura administrá-la, aumentá-la, exercer sobre ela controles precisos e regulações gerais (Foucault, 1978). A partir do século 19 , o poder de morte encontra sua legitimidade na gestão calculada da vida. É em nome da saúde de todos, da vitalidade da espécie, do controle das epidemias, que a biopolítica se transforma e convive com sua fase obscura: a tanatopolítica (Agamben, 2002).

Se pretendermos construir uma história dos saberes relativos ao corpo que seja capaz de prescindir de certezas e reducionismos, que seja capaz de analisar os múltiplos discursos, suas confrontações e alianças, assim como a resistência ou a aceitação das práticas médicas, sem deixar de tornar explícitos os abusos que foram e que ainda são cometidos em nome do bem comum, e do melhoramento da saúde das populações, não poderemos deixar de questionar essa categoria ambígua que é a de biopolitica. Certamente a experimentação com seres humanos é um dos muitos modos pelos quais se manifesta a biopolítica da população que possibilita a consolidação dos estados-nação.

\section{A biopolítica: entre o poder e a dominação}

Foucault considera fato determinante da construção das sociedades modernas o processo pelo qual a vida, isto é, a vida nua, a vida natural que compartimos com os animais, passa a ser investida por cálculos explícitos e por estratégias de poder. $\mathrm{O}$ momento em que a vida ingressa, como elemento privilegiado, no registro da política. Para compreender o alcance e a significação dessa mudança, é preciso entender o papel que a vida ocupava no pensamento grego em relação ao espaço da política. É por oposição à concepção aristotélica de "homem" que Foucault pensa o exercício da biopolítica: Por milenios o homem permaneceu o que era para Aristóteles: um animal vivente e, além disso, capaz de existência política; o homem moderno é um animal em cuja política está em questão a sua vida de ser vivente (Foucault, 1978).

Lembremos que para o pensamento grego o espaço do vital, isto é, o espaço da sobrevivência, da natalidade e da reprodução, era a precondição necessária e imprescindível para participar da vida em comum da Polis. Mas, de fato, nenhuma atividade que servisse só para o propósito de manter o processo vital tinha entrada na esfera da política (Arendt, 1993). A fome, as necessidades, a dor tornavam as pessoas escravas. Era necessário em primeiro lugar que os sujeitos pudessem se libertar da escravidão, que impõe o vital, para então ingressar na esfera do político, no espaço dos direitos. Para romper com essa escravidão, era permitido o uso da força e da violência, ambas alheias àquilo que caracterizava a condição propriamente humana: aquela que se realizava no espaço dialógico e argumentativo da Polis. Não é por acaso que Agamben terá como referência privilegiada de seu texto dois autores: Michel Foucault e Hannah Arendt. Ainda que Arendt nunca tenha falado sobre biopolítica a questão que lhe preocupa é a mesma que preocupa a Foucault, o governo referido exclusivamente à dimensão do vital.

Para poder compreender as dificuldades nesta sobreposição entre vida e política, deveremos fazer uma rápida referência ao pensamento grego, pois como afirma Arendt (1993) os filósofos gregos, seja qual for sua posição a respeito da Polis, não duvidaram de que a liberdade se localiza exclusivamente na esfera política, que a necessidade (o bios) é de maneira fundamental um fenômeno pré-político (...) e que a força e a violência se justificam nessa esfera porque são os unicos meios para dominar a necessidade e chegar a ser livres.

A grande novidade que se produz no mundo moderno, da qual falaram tanto Foucault quanto Arendt e Agamben, está dada pela identificação entre o vital e o político. No mesmo momento em que o homem moderno conquista os direitos que se pretendem universais, é o domínio do vital o que entra em questão. A vida, o corpo, a saúde, as necessidades, a reprodução, que antes faziam parte da esfera pré-política, se transformam nas questões políticas por excelência. As estatísticas contribuem para dotar esse processo de maior objetividade, taxas de mortalidade e morbidade, taxas de natalidade, concentração de epidemias e doenças, todo um novo domínio de saber e de intervenção política que se refere exclusivamente ao espaço do vital e a seus fenômenos correlatos: de natalidade, reprodução e morbi- mortalidade.

Mas falar na novidade que implica a biopolítica da população significa afirmar um processo complexo e de duas faces. Por um lado, o domínio do vital (natalidade, saúde, mortalidade e reprodução) que para os gregos era eminentemente privado passará a fazer parte da es- 
fera do social e conseqüentemente do político. Os direitos das mulheres, das crianças, dos trabalhadores, o reconhecimento dos direitos básicos à alimentação e à assistência, ainda que duramente conquistados, falam da positividade dessa biopolítica. Mas existe outra face, obscura, desse mesmo processo.

Se a condição humana é definida pela vida política e pelo diálogo argumentativo entre iguais, isto é como zoon logon ekhon (como ser vivo capaz de fala); seu contrário, como afirma Arendt (1993), o que caracteriza a vida nua e sem conseqüência política é o aneu logou (sem logos), uma vida sem significação alguma, uma vida que se esgota no próprio fato da sobrevivência, na sua característica única de "ser vivo". A esse "corpo espécie" não lhe correspondem outros direitos mais que sua natalidade, sua reprodução e sua morte. Ela pertence inteiramente ao registro do biológico, da pura corporeidade. Conseqüentemente, suas conquistas e lutas prescindem de argumentos e devem estar fundados na aceitação passiva de ordens ou na violência e na força.

A vida nua, isto é, "a vida matável e insacrificável do Homo Sacer” (Agamben, 2002) persiste nas margens da mesma sociedade que diz garantir os direitos humanos fundamentais e universais. Esse é o paradoxo assinalado, primeiro por Arendt e depois por Agamben, da figura dos "refugiados": A concepção dos direitos do homem e do cidadão, baseada na suposta existência de um ser humano como tal, caiu em ruínas tão logo aqueles que a professavam encontraram-se pela primeira vez diante desse homem (o refugiado) que havia perdido toda e qualquer qualidade e relação específica, exceto o puro fato de ser "humanos" (Arendt, apud Agamben). É preciso observar a funcionalidade estratégica do Homo Sacer. Ele é hoje, como em tempos de Aristóteles, a precondição que permite garantir a existência política e argumentativa entre iguais.

Hoje, como no mundo grego, a política ainda se define em função de uma exclusão fundamental, a daqueles que tem o único estatuto de "corpo espécie" ou "vida nua". Assim como o espaço da necessidade era a precondição da vida comunicativa e ativa da polis, na biopolítica da população é a vida nua, a pura corporeidade se considera a precondição que possibilita a existência propriamente humana da cidadania e dos direitos.

Nesse horizonte, as experimentações com seres humanos podem ser analisadas a partir de uma perspectiva que permita integrar os estu- dos provenientes da bioética com a análise das estratégias biopolíticas referidas às populações situadas nas margens do mundo político regido por leis, normas e estatutos aceitos e discutidos por todos. A partir do momento em que essas populações situadas nas margens da sociedade são reduzidas ao estatuto de "vida nua", elas deixam de ser pensadas como sujeitos de direito para passarem a ser pensadas exclusivamente como corpos vivos. Assim enquanto existem sujeitos que não são reconhecidos como cidadãos com direitos e deveres mas como pura e nua corporeidade, eles podem passar a ocupar esse espaço politicamente perigoso e ambíguo de uma "vida nua".

Mas como compreender essa relação entre sujeitos que pertencem e que não pertencem ao mundo dos direitos, que, a partir de Hannah Arendt, se vincula com os conceitos de nação e de estado a partir do conceito foucaultiano de poder? Sabemos que para Foucault onde existe poder existe resistência, que as relações de poder são reversíveis, móveis e instáveis, mas o espaço da vida nua, da pura e muda força vital parece, muitas vezes, fugir dessa reversibilidade. Então, o que se revela como alheio ao jogo do poder e da resistência, aquela vida que não pode se contrapor aos jogos de poder, pode ser pensada a partir do conceito foucaultiano de "dominação": As relações de poder são cambiantes, reversíveis e instáveis. Deve ser considerado que não podem existir relações de poder a menos que os sujeitos sejam livres. Se um sujeito está completamente à disposição de outro, se ele se tornar uma coisa, um objeto sobre o qual se pode exercer uma violência infinita e ilimitada, não há relações de poder. Para existir uma relação de poder, deve haver, em ambas as partes pelo menos, certa forma de liberdade. Isso significa que nas relações de poder existe necessariamente a possibilidade de resistência. Porém, existem estados de "dominação". Trata-se das relações de poder fixas, perpetuamente assimétricas onde a margem de liberdade é extremamente limitada (Foucault, 1996).

Foucault analisa como exemplo de dominação a relação conjugal na sociedade dos séculos 18 e 19. Perante o poder masculino, a mulher podia responder de formas diversas, sendo infiel, rejeitando sexualmente o marido, etc. Porém, nenhuma dessas pequenas resistências possibilitava que a situação de assimetria fosse verdadeiramente revertida. Ainda se mantinha intacta a distinção grega entre os cidadãos que participam das relações de poder e as mulheres 
a quem estava reservado o espaço doméstico dos aneu logou, dos sem fala. Nas situações de dominação - econômica, institucional, sexual o problema está, de fato, em poder determinar onde e de que modo será organizada a resistência (Foucault, 1996).

No caso da experimentação com seres humanos parece não existir essa mobilidade e reversibilidade do poder. A capacidade de resistência dos sujeitos de experimentação é mínima ou até nula se considerarmos que, muitas vezes, como na experiência de transmissão vertical de HIV analisada, os sujeitos envolvidos não estão sabendo se fazem parte de um ou outro grupo, se serão beneficiados com a medicação ou se receberão placebo. Em tal caso, as respostas possíveis são limitadas. A margem de liberdade para dar respostas aos fatos é quase inexistente, fazendo com que os sujeitos envolvidos possam passar facilmente ao estatuto de cobaias. Eles se definem exclusivamente como "corpo espécie", como vida nua, como alguém que qualquer um pode matar impunemente (Agamben, 2002).

\section{Conclusão}

A biopolítica, modalidade de exercício do poder própria dos estados modernos, no momento que garante a sobreposição entre vida e política, possibilita que com um mesmo gesto sejam definidas as populações que pertencem ao espaço da vida nua e aquelas que fazem parte da vida ativa, isto é, da condição humana que deve ser cuidada, estimulada, multiplicada. Mas para multiplicar a vida e o cuidado com os cidadãos, para garantir seus direitos, seu vigor e sua saúde pode resultar legítimo admitir como precondição o uso experimental de seres humanos sem que eles se beneficiem dos melhores meios diagnósticos e terapêuticos existentes, como é exigido pela Declaração de Helsinque de 1996 ainda em vigor.

Muito antes da Declaração de Helsinque, e muito antes dos atuais debates sobre os dilemas éticos surgidos da realização de ensaios clínicos no Terceiro Mundo (Amann, 2001; Rothman, 2001; Garrafa \& Machado, 2001), as pesquisas realizadas nos trópicos pelos pesquisadores ingleses e franceses nos permitem refletir sobre o papel político da desigualdade nas pesquisas médicas. Muito antes de que fossem utilizadas idéias legitimadoras como "duplo standard" ou "relativismo ético" (Amann, 2001) os pesquisa- dores que se defrontaram com novas civilizações, novas doenças e novas populações nas colônias pobres de Ultramar podiam livremente realizar suas pesquisas com seres humanos sem grandes cuidados, seguindo o argumento utilitarista do benefício futuro que as pesquisas representariam para melhorar o vigor e a saúde das populações.

Nada impedia que os sujeitos de pesquisa, considerados existentes puramente biológicos, fossem pensados como "matáveis". A eles era atribuído um estatuto alheio à "condição humana”: pura corporeidade, vida nua. Como afirma Foucault, esse poder de morte se mantém como o limite exterior da biopolítica: é sobre a vida e sobre seu desenvolvimento que o poder estabelece sua força; a morte é seu limite o momento que não pode ser apresado (Foucault, 1976).

Podemos tentar pensar a defesa atual do chamado "duplo standard" ou do "relativismo ético" em relação a esta oposição entre um poder que toma a vida, o corpo e a saúde a seu cuidado e sua contra-face, um poder de morte que persiste como seu limite, como uma antiga estratégia de poder que se refere à corporeidade nua e sem direitos. Se esse espaço foi ocupado sem maiores questionamentos pelas mulheres e os escravos no pensamento grego; e se, no caso dos pesquisadores ingleses, Manson e Ross, era o espaço da população indiana necessitada de assistência; hoje ainda podemos ouvir as vozes dos que defendem a persistência desse espaço reservado para as populações pobres do Terceiro Mundo. Especificamente, no caso das pesquisas sobre transmissão vertical de HIV, reservado para as populações pobres de África.

Lembremos que depois do debate suscitado pela divulgação dessa pesquisa, a revista The Lancet publica uma declaração de "consenso" redigida por bioeticistas americanos legitimando o "duplo standard" e o "relativismo ético" e criticando um universalismo que é considerado inaplicável, indiferente à realidade dos países do Sul, além de suscetivel de retardar gravemente o progresso das pesquisas contra patologias em expansão (Amann, 2001). Estes pesquisadores nos chamam ao realismo, nos convidam a deixar de ser ingênuos e a deixar de lado o que parecem considerar a velha e gasta idéia de eqüidade. Nos convidam a reconsiderar o caráter moral das pesquisas realizadas, algo que para os pesquisadores ingleses que trabalhavam na Índia não representava nenhum conflito ético. Para eles existiam dois mundos bem delimita- 
dos: a metrópole e as colônias de ultramar; dois mundos que não tinham por que ter as mesmas regras. As desigualdades estavam explicitadas e eram justificadas pela própria lógica colonialista.

Então, se queremos utilizar a história para melhor compreender nosso presente, quiçá possamos afirmar que existe algo que aproxima as pesquisas realizadas no fim do século 19 e inícios do século 20 com as populações nativas das colônias, do debate atual sobre as pesquisas realizadas na África. Podemos procurar essa proximidade na declaração de "consenso" entre pesquisadores que defendem a força do realismo e a aceitação de uma "ética da urgência”. A diferença da lógica colonialista hoje resulta necessário enunciar e justificar o que antes não precisava ser justificado: a existência de dois mundos, o mundo dos direitos e aquele das "exceções", o mundo dos corpos que devem ser cuidados e o mundo habitado por aqueles que têm o estatuto de vida nua, de vidas que foram postas fora da jurisdição humana de modo tal que a violência cometida contra eles não constitui nenhum sacrilégio (Agamben, 2002).

\section{Referências bibliográficas}

Agamben G 2002. Homo Sacer. Ed. UFMG, Belo Horizonte.

Amann J 2001. Droit- Santé et relations Nord-Sud. Éthique médicale et biomédicale. Revue Française des Affaires Sociales 3.

Arendt H 1993. La condición humana. Siglo XXI, México.

Benchimol J 1999. Dos micróbios aos mosquitos. FiocruzUFRJ, Rio de Janeiro.

Benoit-Browaeys 2001. La bioéthique. Les Essentiels Milan, Paris.

Berlinguer G 1996. Ética da saúde. Hucitec, São Paulo.

Bourdieu P 2001. Science de la science et reflexivité. Ed Raisons d'Agir, Paris.

Bynum W \& Overy C (eds.) 1998. The best in the mosquito: the correspondence of Ronald Ross and Patrick Manson. Ed. Rodolpi, Atlanta.

Deleuze G 1987. Foucault. Paidos, Barcelona.

Dozon JP 1991. Pasteurisme, médecine militar et colonisation de Afrique noire, pp. 269-278. In M Morange (org.). L'Institut Pasteur: contributions à son histoire. Ed. La Decouverte, Paris.

Fassin D 2003. Biopolitique, pp. 176-179. In D Lecourt (org.). Dictionaire de la Pensée Medicale. PUF, Paris.

Foucault M 1978. A história da sexualidade I. Siglo XXI, México.

Foucault M 1996. El yo minimalista. Biblioteca de la Mirada, Buenos Aires.

Foucault M 1994. Resumo dos Cursos do Collége de France (1970-1982). Zahar, Rio de Janeiro.

Foucault M 1992. Genealogia do racismo. Caronte, Buenos Aires.

Foucault M 1989. Microfísica do poder. Graal, Rio de Janeiro.

Freitas C \& Hossne W 1998. Pesquisa com seres humanos, pp. 193-204. In Ferreira Costa, Garrafa \& Oselka (orgs.). Iniciação à bioética. Conselho Federal de Medicina. Brasília.

Garrafa V \& Machado M 2001. Mudanças na Declaração de Helsinque: Fundamentalismo econômico, imperialismo ético e controle moral. Cadernos de Saúde Pública 17(6):1489-1496.

Goldim JR \& Rossi R 1999. Glossário de termos científicos para elaboração do Consentimento Informado. Revista de Medicina. 19(1):304-309
Goldim JR 1999. O Caso Tuskegee: quando a ciência se torna eticamente inadequada. Disponível em <www. ufrgs.br/HCPA>. Atualizado em 1999.

Jonas H 1970. Reflexiones filosóficas sobre la experimentación con seres humanos, pp. 17-45. In P Freund (org.). Experimentación con sujetos humanos. Fondo de Cultura Económica, México.

Latour B \& Woolgar S 1997. A vida de laboratório. Relume-Dumará, Rio de Janeiro.

Lecourt D 2000. Prefácio, pp. 9-11. L’humain est-il expérimentable? PUF, Paris.

Löwy I 1991. La mission del Institut Pasteur à Rio de Janeiro: 1901-1905, pp. 279-295. In M Morange (org.). L'Institut Pasteur: contributions à son histoire. Ed. La Decouverte, Paris.

Manson P 1898. Tropical diseases. Cassell and Company, Londres.

Michaud Y 2000. Des modes de subjectivation aux techniques de soi, pp. 11-40. Cités n. 2, ano 2000:11-40. De la Guerre de races ao biopouvoir. PUF, Paris.

Nouvel P 2000. Oui, l'humain est expérimentable, pp. $21-$ 29. In D Lecourt (org.). L'humain est-il expérimentable? PUF, Paris.

Ross R 1998. Correspondence to Manson. In W Bynum \& C Overy (eds.). The best in the mosquito: the correspondence of Ronald Ross and Patrick Manson. Ed. Rodolpi, Atlanta.

Porter R 2000. Cambridge Illustrated History of Medicine. Cambridge University Press.

Porter R 2002. "El pasado de la Medicina: la história y el oficio". Entrevista a Roy Porter de Marcos Cueto. Revista História, Ciência e Saúde. Fiocruz, Rio de Janeiro.

Rothman D 2001. Les nouveaux cobayes de la recherche médicale. La Recherche 344 juillet-août:28-39.

Salomon-Bayet C 2003. Experimentation humaine, pp. 470-475. In D Lecourt (org.). Dictionaire de la Pensée Medicale. PUF, Paris.

Vieira S \& Hossne W 1987. Experimentação com seres humanos. Ed. Moderna, São Paulo.

Artigo apresentado em 4/9/2003

Aprovado em 5/11/2003

Versão final apresentada em 15/3/2004 